$\begin{array}{ll}\text { Abstracta Iranica } & \begin{array}{l}\text { Abstracta Iranica } \\ \text { Revue bibliographique pour le domaine irano-aryen }\end{array} \\ & \text { Volume } \mathbf{2 9 |} \mathbf{2 0 0 8} \\ & \text { Comptes rendus des publications de } \mathbf{2 0 0 6}\end{array}$

\title{
Journal of Inner Asian Art and Archaeology. 1, 2006, Turnhout, Brepols, $169 \mathrm{p}$.
}

Frantz Grenet

\section{OpenEdition}

1 Journals

Édition électronique

URL : http://journals.openedition.org/abstractairanica/25032

DOI : 10.4000/abstractairanica.25032

ISSN : 1961-960X

Éditeur :

CNRS (UMR 7528 Mondes iraniens et indiens), Éditions de l'IFRI

\section{Édition imprimée}

Date de publication : 15 mai 2008

ISSN : 0240-8910

\section{Référence électronique}

Frantz Grenet, « Journal of Inner Asian Art and Archaeology. 1, 2006, Turnhout, Brepols, 169 p. », Abstracta Iranica [En ligne], Volume 29 | 2008, document 42, mis en ligne le 15 septembre 2008, consulté le 26 septembre 2020. URL : http://journals.openedition.org/abstractairanica/25032 ; DOI : https://doi.org/10.4000/abstractairanica.25032

Ce document a été généré automatiquement le 26 septembre 2020.

Tous droits réservés 


\title{
Journal of Inner Asian Art and Archaeology. 1, 2006, Turnhout, Brepols, $169 \mathrm{p}$.
}

\author{
Frantz Grenet
}

1 Premier numéro d'une revue annuelle issue du Circle of Inner Asian Art (SOAS, Londres) et destinée implicitement à remplacer Silk Road Art and Archaeology publié au Japon entre 1993 et 2004. La seconde partie de ce volume inaugural constitue un ensemble en hommage à A.D.H. Bivar. Je signale les articles qui concernent directement les études sur l'Iran et l'Asie centrale préislamiques et apportent des matériaux nouveaux :

2 - D. W. Mac Dowall, «The sequence of Menander's copper coinages »;

3 - A. A. Chaverdi, P. Callieri, « A rural settlement of the Achaemenid Period in Fars »;

4 - Ch. Fabrègues, « Taxila earrings of Achaemenid derivation »;

5 - M. L. Carter, " Notes on Kuṣāna chronology and the Bactrian era » (reconstruction plausible de la partition de l'empire kouchan après l'invasion sassanide ; l'A. accepte pour l'ère kouchane la date de 127/128 proposée par H. Falk, et pour la « seconde ère kouchane » une ère kouchane + 100 instituée au Gandhāra et au Pendjab par Kanishka II, émule conscient de son ancêtre Kanishka I ; cf. dans le même sens H. Falk, « The Kanișka era in Gupta records », Silk Road Art and Archaeology, 10, 2004, pp. 167-176 ; mais la proposition de M. Carter de dater de 233 l'« ère bactrienne " concurrente est maintenant réfutée par $\mathrm{F}$. de Blois, « Du nouveau sur la chronologie bactrienne préhellénistique : l'ère de 223/224 ap. J.-C. », CRAI 2006 [2007] - il s'agit en fait de l'ère d'Ardašīr) ;

6 - B. A. Litvinskij, "Bronzes appliqués of Erotes from the temple of the Oxus. The question of their dating in the light of connections between Rome and Central Asia » (il s'agit d'imitations de modèles romains des $\mathrm{III}^{\mathrm{e}} \mathrm{IV}^{\mathrm{e}} \mathrm{s}$. de n.è., donc en rapport avec l'une des dernières périodes de fonctionnement du temple);

7 - M. Ghose, "Nana: the 'original' goddess on the lion » (recensement exhaustif des images indiennes susceptibles d'être identifiées comme Nana au lion ; cette déesse 
mésopotamienne adoptée en Asie centrale serait, en Inde, restée confinée au culte royal kouchan, et son absorption par l'indienne Durgā se serait produite à Mathurā dès la fin du II ${ }^{\mathrm{e}}$ s. de n.è.) ;

8 - J. A. Lerner, P. O. Skjaervo, "The seal of a eunuch in the Sasanian court » (empreinte du sceau de «Bōxtšăbuhr [...] arzbed », datable du III ${ }^{\mathrm{e}}$ s. ; le terme arzbed, déjà découvert par A. Tafazzoli dans un texte syriaque, signifie " maître des femmes », sur av. hāiriš̌̌"femelle »; discussion sur les personnages imberbes de l'iconographie sassanide, qui selon J. Lerner seraient tous des eunuques - mais certains, dont Kerdirr, étaient des mages, et cela irait à l'encontre des injonctions zoroastriennes sur l'intégrité physique et le devoir de procréer);

9 - P. O. Skjaervo, «A new block from the Paikuli inscription » (un bloc inscrit de Paikuli, auparavant inconnu et apparu sur le marché des antiquités ; il complète le texte connu en ce qui concerne les circonstances de la reddition du jeune roi Wahrām et de son protecteur Wahnām, et mentionne un lieu 'wt..štr'n, non identifié) ;

10 - A. Rahman, F. Grenet, N. Sims-Williams, " A Hunnish Kushan-shah » (une empreinte de sceau provenant du Bunēr au Pakistan septentrional donne le portrait d'un souverain kidarite de Samarkand, c. 450-470, avec une légende bactrienne développée où il porte les titres de « roi des Huns, grand roi des Kouchans, afsīin de Samarkand »);

11 - M. Alram, C. Lo Muzio, "A new coin type of the Khalaj? (deux monnaies de bronze dont l'avers imite le dernier type de Pērōz portent une légende bactrienne *xalasgano ou *xalassano, adj. dérivé de xalaso " Khalaj »; le revers figure Śiva ; la date et le lieu d'émission restent incertains - au $\mathrm{VI}^{\mathrm{e}} \mathrm{s}$. au Tokharistan, alors que les Khalaj faisaient encore partie de l'empire hephtalite, ou au VII ${ }^{\mathrm{e}} \mathrm{s}$. après leur migration au sud de l'Hindukush ?) ;

12 - G. Azarpay, V. A. Livshits, « The MP archive at Berkeley: a pre-Islamic forerunner of 'Samarkand' paper? » (les documents d'archives pehlevis conservés à l'Université de Berkeley, qui portent des dates dans l'ère de Yazdgird III et ont livré des dates C 14 comprises entre 651 et 776, sont écrits sur un tissu de lin imprégné de gypse) ;

13 - M. Schwartz, " From Healer to Hylē: Levantine iconography as Manichean mythology ";

14 - Z. Gulácsi, U. Sims-Williams, "An illustrated parchment folio from a Middle Persian Manichaean codex in the collection of the British Library, Or. 12452D/3 (Kao. 0111)».

\section{INDEX}

Thèmes : 3.0. Généralités 
AUTEURS

FRANTZ GRENET

CNRS - EPHE - Paris 